\title{
Antidiarrheal activity of $80 \%$ methanol extract of the aerial part of Ajuga remota Benth (Lamiaceae) in mice
}

\author{
Teshager Yacob, Workineh Shibeshi and Teshome Nedi*
}

\begin{abstract}
Background: In the Ethiopian traditional medicine, the aerial part of Ajuga remota Benth is used in the treatment of diarrhea. There are different mechanisms by which Ajuga remota may have antidiarrheal effect. Some of the possible mechanisms are through its anthelmintic and antibacterial activity. The present study aimed to evaluate whether the antidiarrheal effect of the plant also include antimotility and antisecretory effect using $80 \%$ methanol extract of $A$. remota (MEAR).

Methods: The MEAR was administered at doses of 200, 400, 600 and $800 \mathrm{mg} / \mathrm{kg}$ to four groups of mice (six animals per group) orally in castor oil diarrhea model. The effect of the extract on enteropooling and gastrointestinal transit model was also evaluated using the same grouping and dosing. Two other groups, one as control and the other as standard (loperamide $5 \mathrm{mg} / \mathrm{kg}$ ) were used for comparison with the treatment groups.

Results: The extract at the doses of 400,600, and $800 \mathrm{mg} / \mathrm{kg}$ produced a dose-dependent and significant inhibition both on the frequency and onset of diarrhea. The percentage purging frequency was 53.4, 66.7, 79.6, and $66.7 \%$ $(p<0.001)$ at three doses of MEAR $(400,600$, and $800 \mathrm{mg} / \mathrm{kg})$ and with loperamide $(5 \mathrm{mg} / \mathrm{kg})$, respectively. The percentage inhibition in intestinal fluid accumulation was $42.5,62.1$, and $74.2 \%(p<0.001)$ at the doses of 400 , 600 and $800 \mathrm{mg} / \mathrm{kg}$ of MEAR, respectively. The MEAR also inhibited the intestinal transit of charcoal meal in a dose dependent manner both in the normal and castor oil induced intestinal transit.
\end{abstract}

Conclusion: This study has shown that the $80 \%$ methanol extract of $A$. remota contains pharmacologically active substances with significant antimotility and antisecretory effect contributing for its antidiarrheal activity.

Keywords: Ajuga remota, Antidiarrheal activity, Castor oil, Enteropooling

Abbreviations: A. bracteosa, Ajuga bracteosa; A. integrifolia, Ajuga integrifolia; A. remota, Ajuga remota; ADI, Antidiarrheal index; ANOVA, Analysis of variance; CCB, Calcium channel blockers; HIV, Human

immunodeficiency virus; LM, The distance traveled by the charcoal meal; LSI, Length of the intestine from pylorus to the caecum; MEAR, Methanol extract of Ajuga remota; PG, Prostaglandin; PI, Peristaltic index; PO, Per os

\section{Background}

Plant extracts are some of the most attractive sources of new drugs and have shown to produce promising results in the treatment of diarrhea [1]. There is a continuous and urgent need to discover new antidiarrheal compounds with diverse chemical structures and novel mechanisms of action. Therefore, researchers are increasingly turning

\footnotetext{
* Correspondence: teshome.nedi@aau.edu.et

Department of Pharmacology and Clinical Pharmacy, School of Pharmacy, Addis Ababa University, P.O.Box 1176, Addis Ababa, Ethiopia
}

their attention to folk medicine, looking for new leads to develop better drugs against diarrheal diseases $[2,3]$.

Ajuga remota is an erect rhizomatous pubescent herb that belongs to the genus Ajuga, found growing in the grasslands and other geographic parts of East Africa especially in Kenya and Ethiopia [4]. In Ethiopia, one of the vernacular name of $A$. remota is Armagusa (oromiffa), the name given by the community that uses this plant for the management of diarrhea [5]. The herb is not eaten by animals, birds or insects. This is probably due to the very bitter taste of almost all its parts [4]. The species $A$. 
remota is also known by other names such as $A$. integrifolia Buch.-Ham, and A. bracteosa Wall.ex.Benth [6].

Several studies are conducted on many species of the genus Ajuga and their active compounds have been identified. These efforts have led to the isolation of a number of compounds, including phytoecdysteroids [7], neo-clerodane diterpenes, diterpenoids (ajugarin I, II, III, IV \&V, and others) [8], triterpenes, specific-sterols like beta-sitosterol, gamma-sitosterol, ceryl alcohol, anthocyanidin-glucosides, iridoid glycosides [4, 9], flavonol glycosides [4], quinolones, withanolides, flavonoids, tannins, triglycerides and essential oils [10].

In East Africa, plants of the genus Ajuga have been used as a remedy for fever, toothache, severe stomachache, dysentery, high blood pressure, malaria, edema, pneumonia and liver problems [4, 10]. In North Africa, plants of the genus Ajuga are used to treat diabetes and hypertension, as a panacea (cure-all), specifically for gastrointestinal disorders, and as an anthelmintic [10]. In traditional Chinese pharmacopoeia, plants of the genus Ajuga are known to produce a diuretic effect $[10,11]$. Other ethnobotanical claims of the plant include treatment of diarrhea, gout, jaundice, amenorrhea, yellow fever, and as antiinfective $[4,5,12]$.

Pharmacological studies have been carried out with $A$. remota since 1976 and it has been reported that $A$. remota possesses antimalarial activity [4], analgesic activity [13], anti-Human Immunodeficiency Virus Type 1 (HIV-1) and Type 2 (HIV-2) activity [14], antioxidant /oxygen scavenging activity [15], diuretic activity [11], antibacterial activity [16] as well as anthelmintic activity [14]. There are different mechanisms by which $A$. remota may have antidiarrheal effect. Some of the possible mechanisms are through its anthelmintic and antibacterial activities. The published reports on traditional use of $A$. remota for the treatment of diarrhea $[5,12]$ and the reported anthelmintic and antibacterial activity studies $[14,16]$ clearly warrant further scientific studies on antidiarrheal effect. Therefore, the present study aimed to evaluate whether the antidiarrheal effect also include antimotility and antisecretory effect using $80 \%$ methanol extract of $A$. remota.

\section{Methods}

\section{Chemicals}

The chemicals used in the experiment include distilled water (Ethiopian Pharmaceutical Manufacturing, Ethiopia), loperamide $\mathrm{HCl}$ (Daehwa Pharmaceutical, Republic of Korea), castor oil (Remkaln General Trading P.LC., Amman Pharmaceutical Industries Co., Jordan), methanol (CARLO ERBA reagents, Germany), tween 80 (Atlas Chemical Industries Inc., UK), activated charcoal (India), chlorform (Finkem Laboratory Reagent, India), atropine sulphate inj.(0.1 \%) (Jeil Pharm.Co.,Ltd., Korea).

\section{Plant material}

The aerial parts of the plant $A$. remota were collected from a place called Karakore, which is located in Kolfe Keraniyo sub-city, Woreda 02 near to Medhanealem church in western part of Addis Ababa in December 2013. Identification and authentication of the plant specimen was done by a taxonomist at the National Herbarium, College of Natural and Computational Sciences, Addis Ababa University, where a voucher specimen (Voucher Specimen number TY001) has been deposited for future reference.

\section{Experimental animal}

Swiss albino mice of either sex bred in the animal house unit of School of Pharmacy and having weights ranging from 20 to $30 \mathrm{~g}$ were used for the experiment. The mice were housed in cages, consisting of 6-10 mice per cage, under standard environmental conditions (a $12 \mathrm{~h} / 12 \mathrm{~h}$ light/dark cycle); they were acclimatized for a period of 7 days before beginning the actual experiment and were provided with the standard laboratory pellet and tap water ad libitum. The care and handling of mice were in accordance with internationally accepted guidelines for use of animals [17] and were approved by Research and Ethics committee of School of Pharmacy, Addis Ababa University.

\section{Extraction of the plant material}

After collection, the aerial parts of the plant were cleaned to remove dust and dirt then sliced to smaller pieces and dried at room temperature under shade for more than 3 weeks. The dried and sliced pieces were then powdered finely using mortar and pestle and subjected to extraction.

\section{Preparation of $\mathbf{8 0} \%$ methanol extract}

Maceration technique was used for the extraction of plant material using $80 \%$ methanol. One hundred gram of the aerial parts of the powdered plant material was subjected to maceration process with about $500 \mathrm{ml}$ of $80 \%$ methanol at room temperature for $72 \mathrm{~h}$ while shaking occasionally. The extract was then filtered through a muslin cloth and Whatman No.1 filter paper and the marc was remacerated twice using the same volume of solvent to exhaustively extract the plant material. The methanol was then removed from the extract by evaporation under reduced pressure using a rota vapor (BUCHI Rota vapour R-200, Switzerland) at $40{ }^{\circ} \mathrm{C}$. The extract was then dried using a lyophilizer to remove the remaining water. The resulting dry hydroalcoholic extract was weighed and calculated for percentage yield, which was $15.5 \% \mathrm{w} / \mathrm{w}$. The dried plant extract was reconstituted with $2 \%$ tween 80 for oral administration. 


\section{Experimental design Grouping and dosing}

Animals were randomly assigned into six groups each consisting of six mice of either sex (weighing 20-30 g) and were fasted for $18 \mathrm{~h}$ before the test with free access to water for antidiarrheal test. Negative controls were treated with the vehicle used for reconstitution $(10 \mathrm{ml} / \mathrm{kg})$, $2 \%$ tween $80 \mathrm{v} / \mathrm{v}$. Positive controls were treated with standard drug, loperamide $\mathrm{HCl}(5 \mathrm{mg} / \mathrm{kg})$ or atropine sulphate $(3 \mathrm{mg} / \mathrm{kg})$ depending on the type of the model used. Four treatment groups were treated with four different doses of MEAR; 200, 400, 600 and $800 \mathrm{mg} / \mathrm{kg}$ orally by using oral gavage. Dose selection was made based on the pilot test performed prior to commencement of the actual experiment.

\section{Antidiarrheal activity}

\section{Castor oil induced diarrhea model}

The experiment was carried out according to the method described by Yadav and Tangpu [18]. After $1 \mathrm{~h}$ of treatment with extract, $2 \%$ tween 80 or standard drug, diarrhea was induced by administration of $0.5 \mathrm{ml}$ of castor oil orally to each mouse. The mice were then housed individually in transparent metabolic cages, the bottom of which was lined with white sheet of paper for observation of the number and consistency of fecal droppings. The papers were changed every hour to make the fecal droppings visible for counting and to check stool consistency. During observation period of $4 \mathrm{~h}$, the onset of diarrhea, the number and weight of both dry and wet stools excreted by the animals were recorded and compared with the control for assessing the antidiarrheal activity. The onset was measured as the time interval in minutes between the administration of castor oil and the appearance of the first diarrheal stool. The total number of diarrheal feces of the control group was considered $100 \%$. Percent inhibition (PI) was calculated as follows;

$P I=\frac{\text { Mean number of wet stools of }(\text { control group-treated group })}{\text { Mean number of wet stools of control group }} \times 100$

\section{Castor oil-induced enteropooling}

Intraluminal fluid accumulation was determined using the method of Maxwell [19], with slight modifications. After $1 \mathrm{~h}$ of treatment with extract, $2 \%$ tween $80(\mathrm{v} / \mathrm{v})$ or standard drug, $0.5 \mathrm{ml}$ castor oil was administered orally to each mouse to induce diarrhea. One hour after castor oil treatment, all mice were sacrificed by cervical dislocation, and the small intestine was ligated both at the pyloric sphincter and at the ileocecal junctions and dissected out. The small intestine was weighed. The intestinal contents were collected by milking into a graduated tube and the volume was measured. The intestines were reweighed and the differences between full and empty intestines were calculated.

\section{Normal gastrointestinal transit in mice}

Normal gastrointestinal transit was investigated in mice according to the methods described by Bakare et.al and Shakuntala et.al $[20,21]$. One hour after the administration of $2 \%$ tween $80(\mathrm{v} / \mathrm{v})$, extract or standard drug, each animal was given $1 \mathrm{ml}$ standard charcoal meal (10\% activated charcoal suspension in $2 \%$ tween 80 ). The mice were then sacrificed $1 \mathrm{~h}$ after the administration of the charcoal meal, the abdomen were opened and the small intestine was immediately isolated. The length of the intestine from pylorus to the caecum (LSI) and the distance traveled by the charcoal (LM) were measured. The peristaltic index (PI) for each mouse was calculated, expressed as percentage of the distance traveled by the charcoal meal relative to the total length of the small intestine. The percentage inhibition relative to the control was also calculated as:

$$
P I=L M / L S I \times 100 \%
$$

Where: $\mathrm{PI}=$ Peristaltic Index

LM = Length of Charcoal Meal; LSI = Length of Small Intestine

$\%$ Inhibition $=\frac{\text { Mean of distance travelled by marker of }(\text { Control }- \text { Test }) \text { group }}{\text { Mean of distance travelled by marker of control group }} \times 100$

\section{Castor oil induced gastrointestinal transit in mice}

This experiment was carried out using the method described by Al-Taher [22]. One hour after the administration of $2 \%$ tween $80 \mathrm{v} / \mathrm{v}$, extract or standard drug, castor oil $(0.5 \mathrm{ml} /$ mouse $)$ was administered orally to these animals to induce diarrhea. After $1 \mathrm{~h}$ of castor oil administration, all animals received $1 \mathrm{ml}$ of charcoal meal marker (10\% charcoal suspension in $2 \%$ tween 80) orally. All the animals were sacrificed after $1 \mathrm{~h}$ of marker administration and the small intestine was rapidly dissected out and placed on a clean white sheet of paper that was stretched on top surface of the table. The intestine was carefully inspected and the distance travelled by charcoal meal plug from the pylorus to caecum was measured and expressed as a percentage of the total distance of the small intestine. The length of the whole intestine was also measured.

\section{In vivo antidiarrheal index (ADI)}

The in vivo antidiarrheal index (ADI in vivo) was then expressed according to the formula developed by Aye-Than as described [23]. 


\section{ADI in vivo $=\sqrt[3]{(D \text { freq }} \times \mathbf{G ~ m e q} \times \mathbf{P}$ freq $)$}

where, $\mathbf{D}$ freq is the delay in defecation time or diarrheal onset (as \% of control),

$\mathbf{G}_{\text {meq }}$ is the gut meal travel reduction (as \% of control), and

$\mathbf{P}_{\text {freq }}$ is the purging frequency, or reduction in the number of stools (as \% of control).

\section{Phytochemical analysis}

Phytochemical tests were carried out for the methanol extract of the plant using standard procedures [24, 25] to identify the presence of secondary metabolites, including alkaloids, flavonoids, terpenoids, tannins, phenolics, anthraquinones, glycosides, steroids, and saponins.

\section{Statistical analysis}

The results were expressed as mean \pm SEM and they were analyzed statistically using One way ANOVA followed by post-hoc tukey test to find out significance difference between control group against each test groups separately. The value of $P<0.05$ was considered statistically significant. Dose-dependent effect was confirmed using linear regression analysis. Data were tested for a normal distribution using Shapiro-Wilk's normality test.

\section{Results}

\section{Castor oil-induced diarrhea}

Pretreatment of mice at the doses of 400, 600, and $800 \mathrm{mg} / \mathrm{kg}$ of MEAR caused a concentration-dependent and significant decrease in the frequency of stooling ( $\mathrm{Re}-$ gression coefficient; $R^{2}=1$, for both), decrease in the weight of wet stools $\left(R^{2}=0.963\right)$, and delay in the onset of diarrhea $\left(R^{2}=0.995\right)$. The percentage purging frequency relative to controls was 53.7, 66.7, 79.6, and $66.7 \%(p<0.001)$ at three doses of MEAR $(400,600$, and $800 \mathrm{mg} / \mathrm{kg}$ ) and with loperamide $(5 \mathrm{mg} / \mathrm{kg})$, respectively as shown in Table 1 . The percentages relative to controls for diarrhea onset were $93.7(p<0.01)$, 145.7, and $183.5 \%(p<0.001)$ at the doses of 400,600 , and $800 \mathrm{mg} / \mathrm{kg}$ of MEAR, while with loperamide $(5 \mathrm{mg} / \mathrm{kg}$ ) this value was $137.3 \%(p<0.001)$ compared to controls as shown in Table 1. The extract at the dose of $200 \mathrm{mg} / \mathrm{kg}$ had no significant effect whereas at the dose of $800 \mathrm{mg} / \mathrm{kg}$ produced maximal inhibitory effect on all the diarrhea parameters measured; similar results were obtained for all the other models tested below.

\section{Castor oil induced enteropooling}

Percentage inhibition in intestinal fluid accumulation was $42.4,62.1$, and $74.2 \%(p<0.001)$ at the doses of 400,600 and $800 \mathrm{mg} / \mathrm{kg}$ of MEAR, respectively, and with loperamide $\mathrm{HCl}(5 \mathrm{mg} / \mathrm{kg})$ this value was $66.6 \%$ $(p<0.001)$ as shown in Fig. 1. The extract showed a dose-dependent inhibition $\left(R^{2}=0.981\right)$ in castor oil induced intestinal fluid accumulation. Similar results were obtained for the weight of intestinal content at the different doses of the extract, compared to the control group as shown in Fig. 2.

\section{Normal gastrointestinal propulsion in mice}

The MEAR inhibited the normal intestinal transit of charcoal meal plug by 35.4, 49.1, and $63.9 \%(p<0.001)$ at the doses of 400, 600 and $800 \mathrm{mg} / \mathrm{kg}$, respectively, while atropine sulphate at the dose of $3 \mathrm{mg} / \mathrm{kg}$ showed $55.0 \%(p<0.001)$ inhibition as shown in Table 2 . The extract inhibited significantly the normal intestinal propulsion in a dose dependent manner $\left(R^{2}=1.000\right)$.

\section{Castor oil induced gastrointestinal transit in mice}

The MEAR inhibited the intestinal transit of charcoal meal induced by castor oil by 33.3, 53.8 and $64.6 \%$ $(p<0.001)$ at the doses of 400,600 and $800 \mathrm{mg} / \mathrm{kg}$, respectively, while atropine sulphate at the dose of $3 \mathrm{mg} / \mathrm{kg}$ showed $61.4 \%(p<0.001)$ inhibition. The extract inhibited significantly in castor oil induced intestinal transit in a dose dependent manner $\left(R^{2}=1.000\right)$.

\section{In vivo antidiarraheal index}

The antidiarrheal index (ADI) is a measure of the combined effects of these different components of diarrhea such as purging frequency, onset of diarrheal stools, and intestinal fluid accumulation. Results for the in vivo antidiarraheal indices were 16.3, 60.8, 80.5 and $98.1 \%$

Table 1 Effect of the $80 \%$ methanol extract of $A$. remota on castor oil induced diarrhea in mice

\begin{tabular}{|c|c|c|c|c|c|}
\hline Group (mg/kg) & Onset of diarrhea (min) & Mean wt. of wet stools in $4 \mathrm{~h}(\mathrm{~g})$ & Mean no. of wet stools in $4 \mathrm{~h}$ & Total no. of stools in $4 \mathrm{~h}$ & $\mathrm{PI}$ \\
\hline Control & $67.00 \pm 2.51$ & $0.69 \pm .04$ & $9.00 \pm 1.09$ & $11.00 \pm 1.26$ & \\
\hline Loperamide5 & $174.33 \pm 14.99^{\mathrm{a}^{* * *}}$ & $0.22 \pm .05^{\mathrm{a}^{* * *}}$ & $3.00 \pm .73^{a^{* * *}}$ & $4.00 \pm .07 \mathrm{a}^{* * *}$ & $66.7 \%$ \\
\hline MEAR 200 & $94.67 \pm 1.64^{b * * c^{* * *} d^{* *}}$ & $0.53 \pm .02^{\mathrm{b}^{* * *} c^{* * *} \mathrm{~d}^{* *}}$ & $6.83 \pm .60^{b^{* *} c^{* * *} d^{* *}}$ & $10.00 \pm .57^{\mathrm{b**} c^{* * *} \mathrm{~d}^{* * *}}$ & $12.9 \%$ \\
\hline MEAR 400 & $151.33 \pm 1.42^{\mathrm{a}^{* * * * * *}}$ & $0.35 \pm .01^{\mathrm{a}^{* * *}}$ & $4.17 \pm .30^{\mathrm{a}^{* * * *} c^{*}}$ & $6.00 \pm .73^{\mathrm{a}^{* * f * * *}}$ & $53.7 \%$ \\
\hline MEAR 600 & $164.67 \pm 15.14^{\mathrm{a}^{* * *}}$ & $0.28 \pm .05^{\mathrm{a}^{* * *}}$ & $3.00 \pm .63^{a^{* * *}}$ & $4.00 \pm .85^{\mathrm{a}^{* * *}}$ & $66.7 \%$ \\
\hline MEAR 800 & $190.00 \pm 19.65^{\mathrm{a}^{* * *}}$ & $0.15 \pm .05^{\mathrm{a}^{* * *} \mathrm{e}^{*}}$ & $1.83 \pm .60^{\mathrm{a}^{* * *}}$ & $2.00 \pm .94^{\mathrm{a}^{* * *}}$ & $79.6 \%$ \\
\hline
\end{tabular}

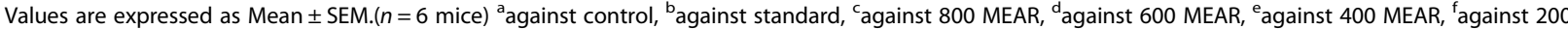
$\operatorname{MEAR}{ }^{*} p<0.05,{ }^{* *} p<0.01,{ }^{* * *} p<0.001$, numbers refers to dose in $\mathrm{mg} / \mathrm{kg}$, PI refers to percent inhibition of defecation 


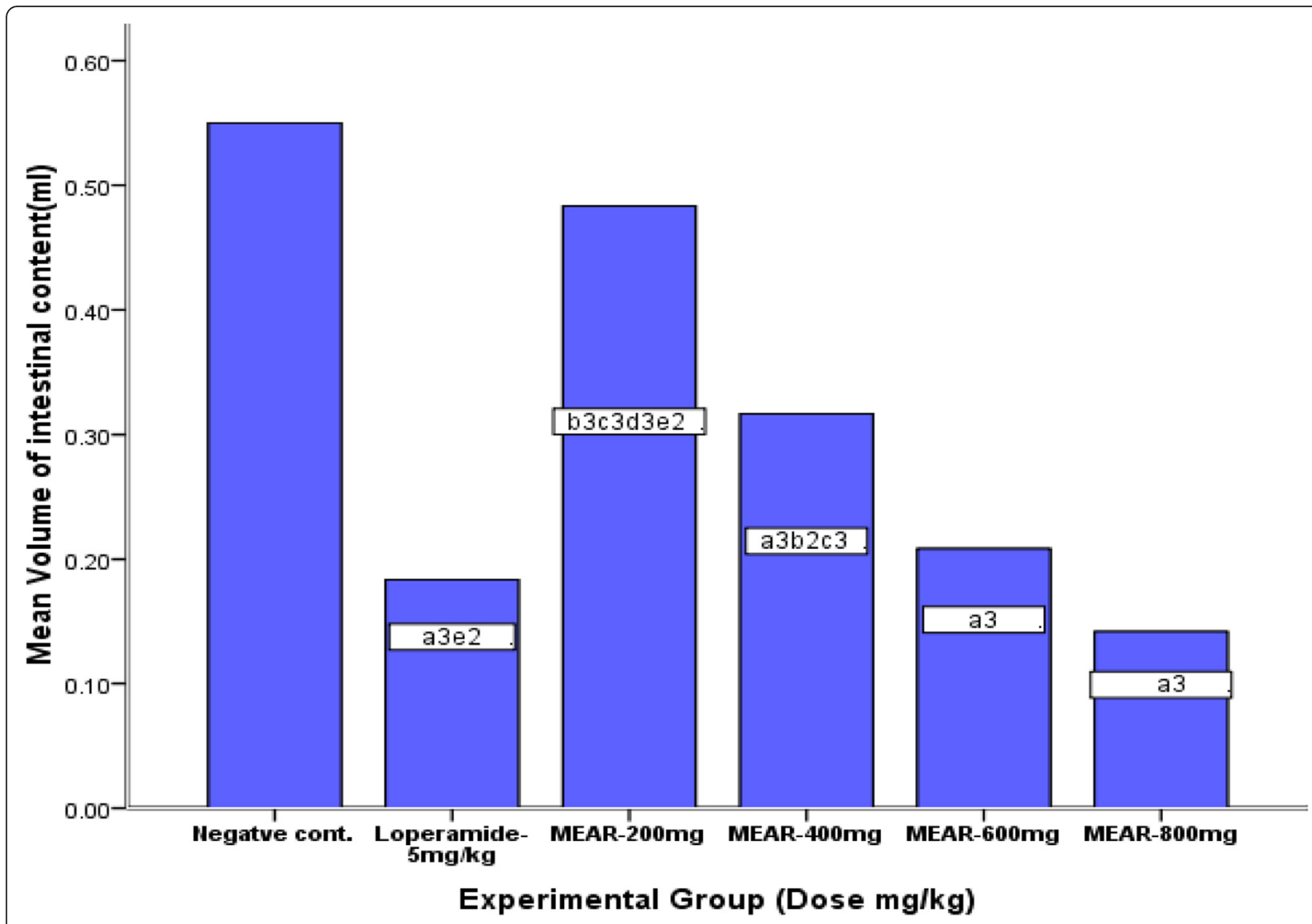

Fig. 1 Effects of MEAR and controls on castor oil-induced enteropooling (volume of intestinal content) in mice $(n=6)$. Data are mean \pm SEM. ${ }^{a}$ against control, ${ }^{b}$ against standard, ${ }^{c}$ against 800 MEAR, ${ }^{d}$ against 600 MEAR, eagainst 400 MEAR, ${ }^{1} p<0.05,{ }^{2} p<0.01,{ }^{3} p<0.001$. MEAR refers to $80 \%$ methanol extract of Ajuga remota, control: groups treated with $10 \mathrm{ml} / \mathrm{kg} 2 \%$ tween 80

at the doses of 200, 400, 600 and $800 \mathrm{mg} / \mathrm{kg}$, p.o. of MEAR respectively, while the $800 \mathrm{mg} / \mathrm{kg}$ of the extract gave a maximum index of $98.1 \%$. The extract produced antidiarrheal activity as shown by the antidiarrheal index in a dose dependent manner $\left(R^{2}=1.000\right)$.

\section{Phytochemical analysis}

The phytochemical analysis of MEAR tested positive for alkaloids, flavonoids, terpenoids, tannins, phenolics, anthraquinones, glycosides, steroids, and saponins.

\section{Discussion}

This study was carried out to evaluate the antidiarrheal activity of the plant extract of $A$. remota in experimental animals, and determine the possible mechanism of action. We have evaluated the acclaimed properties of the plant using different animal models. Relevantly, the $80 \%$ methanol extract of the aerial parts of $A$. remota showed a statistically significant and dose-dependent inhibition in all diarrheal parameters: onset of diarrhea, weight of wet stools, number of wet stools, and total number of stools as compared to the control group. This result is in accordance with previous claims in respect of antidiarrheal herbs. Antidiarrheal plants are known to reduce number of wet stools, consistency of fecal droppings as well as delay in the onset of diarrhea as reported for Pterocarpus erinaceus [19], Saussurea lappa, Lithocarpus dealbata and Urena lobata [18].

Castor oil was used in this study to induce diarrhea since castor oil model, incorporates both secretory and motility diarrhea [26-28]. Castor oil is composed principally of ricinoleic acid [29]. The ricinoleic acid readily forms ricinoleate salts with $\mathrm{Na}^{+}$and $\mathrm{K}^{+}$in the lumen of the intestine. Ricinoleate has several actions that could account for its anti-absorptive effect on the mucosa. It inhibits the enzyme $\mathrm{Na}^{+}-\mathrm{K}^{+}$ATPase and increases the permeability of the intestinal epithelium [30, 31]. Thus; one possible anti-diarrheal activity of the extract against castor oil induced diarrhea may be attributed to its antielectrolyte permeability action [30]. Ricinoleic acid also causes local irritation and inflammation of the intestinal mucosa leading to prostaglandin (PG) release, which causes an increase in the net secretion of water and electrolytes into the small intestine $[30,32]$. Inhibitors of 


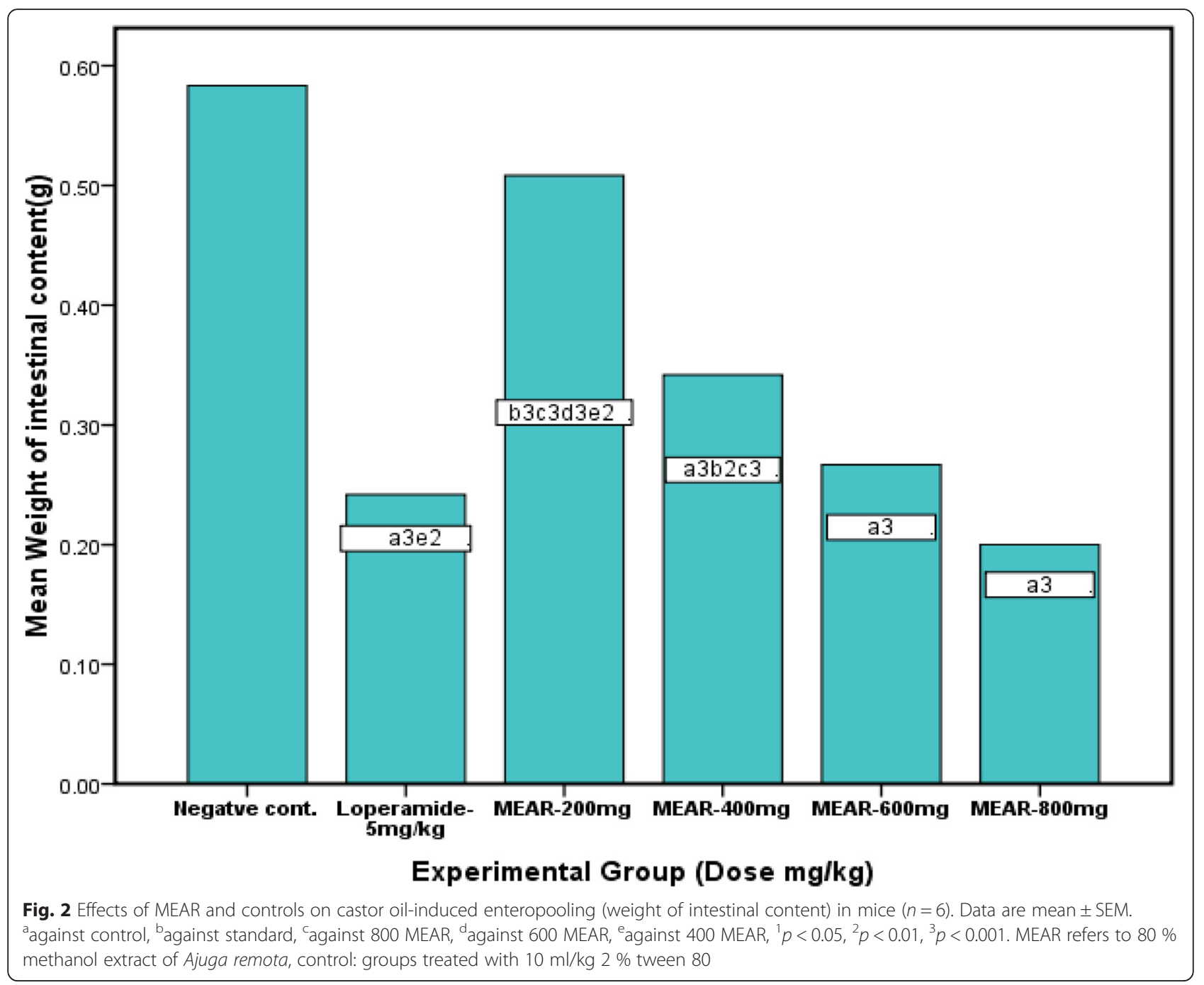

prostaglandin biosynthesis delayed castor oil induced diarrhea [33]. Based on these facts, it is reasonable to suggest that the extract may reduce PG induced secretion of water and electrolytes due to the inhibition of prostaglandin synthesis [34]. Investigations of the mode of action indicate that tannins and flavonoids present in the plant may increase colonic water and electrolyte reabsorption [3]. Thus, in general the antidiarrheal activity of the extract against experimentally induced diarrhea by castor oil may be attributed to an increase in fluid and electrolytes absorption and/or to a slowing down of intestinal transit, allowing more time for absorption to occur since castor oil induces acceleration of the intestinal transit because of its motor activities and

Table 2 Normal gastrointestinal transit in mice treated with the $80 \%$ methanol extract of $A$. remota

\begin{tabular}{|c|c|c|c|c|}
\hline Group (mg/kg) & Mean of the total length of intestine $(\mathrm{cm})$ & $\begin{array}{l}\text { Mean of distance traveled by } \\
\text { charcoal meal }(\mathrm{cm})\end{array}$ & Peristaltic index (PI) & (\%) Inhibition \\
\hline Control & $57.77 \pm 1.09$ & $40.74 \pm 1.25$ & 70.51 & 0.0 \\
\hline Atropine 3 & $55.96 \pm 1.28$ & $18.33 \pm 0.56^{{ }^{* * *} e^{*}}$ & 32.76 & 55.0 \\
\hline MEAR 200 & $55.71 \pm 1.11$ & $37.56 \pm 1.51^{b^{* * * *} c^{* * * *} d^{* * * *} e^{* * *}}$ & 67.43 & 7.7 \\
\hline MEAR 400 & $53.58 \pm 0.93$ & $26.28 \pm 2.15^{\mathrm{a}^{* * *} \mathrm{~b}^{*}}$ & 49.05 & 35.5 \\
\hline MEAR 600 & $54.47 \pm 1.17$ & $20.70 \pm 1.18^{\mathrm{a}^{* * *}}$ & 38.00 & 49.2 \\
\hline MEAR 800 & $55.30 \pm 1.21$ & $14.69 \pm 0.55^{a^{* * * *} e^{* * *}}$ & 26.58 & 63.9 \\
\hline
\end{tabular}

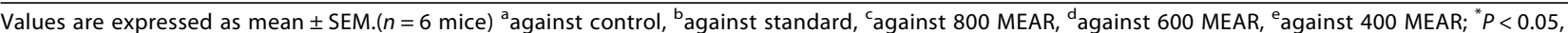
${ }^{* *} p<0.001,{ }^{* * *} p<0.001 .200,400,600$ and $800 \mathrm{mg} / \mathrm{kg}$ represent doses of MEAR; Control: control group taking $10 \mathrm{ml} / \mathrm{kg} 2 \%$ tween 80 , Atropine : Atropine sulphate $3 \mathrm{mg} / \mathrm{kg}$ 
prevent absorption of water and solutes in the lower intestine [34].

Studies on castor oil - induced intestinal fluid accumulation showed that the extract reduced both the weight and volume of intraluminal contents. These effects, which are direct consequences of reduced water and electrolytes secretion into the small intestine, suggest that the extract may enhance electrolyte absorption from the intestinal lumen consistent with inhibition of hypersecretion [35]. Again it is likely that the enhanced electrolyte absorption by the extract may have encouraged the absorption of other intestinal solute contents like nutrients that in turn may have created an osmotic gradient across enterocytes which stimulated water absorption [35]. Thus, another possible antidiarrheal activity of the extract could be the reduction in net fluid and solutes secretion, since a great part of the laxative effect of castor oil is related to increase in fluid secretion [34] and this fluid content is the principal determinant of stool volume and consistency [30].

Tannins present in plant, denature proteins in the intestinal mucosa forming protein tannate complex. The complex forms a coat over the intestinal mucosa and makes the intestinal mucosa more resistant to chemical alteration and reduces secretion $[10,36]$. In addition, flavonoids present antioxidant properties which are presumed to be responsible for the inhibitory effects exerted upon several enzymes including those involved in the arachidonic acid metabolism [37], thus, reducing prostaglandin induced fluid secretion. Furthermore, a previous study has also shown that the plant possesses anti-oxidant activity [15].

The $80 \%$ methanol extract of $A$. remota inhibited gastrointestinal propulsion in both the normal or castor oil induced intestinal transit. This finding suggests that the extract acts on all parts of the intestine. A decrease in the motility of gut muscles increases the stay of substances in the intestine. This allows better water and electrolyte absorption. This is indicative of the ability of the plant to alter normal peristaltic movement and hence decrease the movement of materials in the intestinal tract allowing greater time for absorption [21, 26]. MEAR changed normal intestinal transit in mice at doses showing antidiarrheal activity. Since the extract shows antipropulsive effect on normal intestine similar to atropine it is likely that the antidiarrheal effect could be due to anticholinergic activity.

Investigations on the mode of action indicate that phytochemicals like phenolics, alkaloids and terpenoids act by inhibiting intestinal motility [3]. Apart from this, flavonoids have been ascribed to their ability to inhibit intestinal motility and electrolytic secretion [3], as well as contractions induced by spasmogenics [34]. Studies on the functional role of tannins also revealed that they can also reduce the peristaltic movements and intestinal secretions by reducing the intracellular $\mathrm{Ca}^{2+}$ inward current or by activation of the calcium pumping system (which induces the muscle relaxation) [22] attributed by spasmolytic and calcium channel blocking (CCB) activities of tannins present in the plant extract [38]. Sesquiterpenes, diterpenes, terpenes, and other terpenoid derivatives are known for inhibiting release of autocoids and prostaglandins, thereby inhibit the motility and secretion induced by castor oil [39].

Hypermotility characterizes forms of diarrhea where the secretory component is not the causative factor [35]. Pre-treatment with the extract suppressed the propulsive movement of charcoal meal plug through the gastrointestinal tract in castor oil induced gut transit which clearly indicates that the aerial parts of the plant extract may be capable of reducing the frequency of stooling in diarrheal conditions. Delay in gastric motility causes further absorption of water from feces and may additionally contribute to reducing its watery texture. From the results of this study, it is likely that the extract inhibits gastrointestinal hypermotility in diarrhea through anticholinergic alkaloids present in A.remota [35, 38].

The antidiarrheal index (ADI) is a measure of the combined effects of these different components of diarrhea such as purging frequency, onset of diarrheal stools, and intestinal fluid accumulation [23]. The $80 \%$ methanol extract of the aerial parts of $A$. remota produced a dose-dependent antidiarrheal index which implies that the plant extract produces antidiarrheal activity in a dose-related manner. The plant has also been shown to possess antibacterial, antiviral, antifungal, and anthelmintic properties $[10,26]$. Such activities of the plant could account additional benefit providing a wider cover for its use in diarrhea of different etiologies including those of infectious diarrheas and thus can serve as a profitable alternative for treating such diarrheas [10, 26]. This study has been undertaken by using a crude hydroalcoholic extract, and that the different biological activities assayed herein, may not be due to a single constituent since the crude extracts contain several compounds acting on different mechanisms. In addition, the interplay of the constituents in the crude extract may result in better activity due to synergism or may lead to a decrease in toxicity and it is possible that pure compounds may not necessarily behave in the same manner as the natural extracts $[3,24]$.

\section{Conclusion}

This study has shown that the $80 \%$ methanol extract of A. remota contains pharmacologically active substances with significant antimotility and antisecretory effect contributing for its antidiarrheal activity in all experimental models used in the study. These attributes may provide the rationale for the use of $A$. remota for treating diarrhea and hence, on a preliminary basis it can be claimed as a potential therapeutic option in the effective management 


\section{of diarrhea, thus supporting its folkloric use by traditional healers for this purpose.}

\section{Acknowledgements}

We acknowledge Aman College of Health Sciences for granting scholarship to the first author.

\section{Funding}

The research was funded by the School of Graduate Studies of Addis Ababa University.

\section{Availability of data and materials}

Data are all contained within the manuscript.

\section{Authors' contributions}

TY conceived the study, designed and conducted all laboratory experiments; analyzed and interpreted experimental results. WS and TN participated in the proposal development, study design and manuscript preparations. All authors read and approved the final manuscript.

\section{Competing interests}

The authors declare that they have no competing interest.

\section{Consent for publication}

Not applicable

\section{Ethics approval and consent to participate}

This study makes use of mice and the experimental protocol for the use of animals was in accordance with internationally accepted guidelines for the use of animals and was approved by Research and Ethics Committee of the School of Pharmacy of Addis Ababa University, Addis Ababa, Ethiopia.

Received: 7 November 2015 Accepted: 10 August 2016

Published online: 22 August 2016

\section{References}

1. Regassa R. Assessment of indigenous knowledge of medicinal plant practice and mode of service delivery in Hawassa city, southern Ethiopia. J Med Plant Res. 2013;7(9):517-35.

2. Najmur RMA, Muhammad R, Mehjabeen, Noor J, Rizwan A. Phytochemical, antimicrobial, insecticidal and brine shrimp lethality bioassay of the crude methanolic extract of Ajuga parviflora Benth. Pak J Pharm Sci. 2013;26:751-6.

3. Palombo EA. Review article; phytochemicals from traditional medicinal plants used in the treatment of diarrhea: modes of action and effects on intestinal function. Phytother Res. 2006:20:717-24.

4. Kuria KAM, De Coster S, Muriuki G, Masengo W, Kibwage I, Hoogmartens J. Antimalarial activity of Ajuga remota Benth (labiatae) and Caesalpinia volkensii harms (Caesalpiniaceae): in vitro confirmation of ethnopharmacological use. J Ethnopharmacol. 2001;74:141-8.

5. Parvez N, Yadav S. Ethnopharmacology of single herbal preparations of medicinal plants in Asendabo district, Jimma, Ethiopia. Indian J Traditional Med. 2010;9(4):724-9.

6. Hedberg I, Kelbessa E, Edwards S, Demissew S, Person E. Flora of Ethiopia and Eritrea: gentianaceae to cyclocheilaceae (volume 5). Addis Ababa, Uppsala: Addis Ababa University; 2006.

7. Kubo I, Lee YW, Balogh-Nair V, Nakanish K, Chapya A. Structure of ajugarins. J Chem Soc Chem Commun. 1976;949-50.

8. Manguro LOA, Ogur JA, Okora DM, Wagai SO, Lemmen P. Further flavonol and iridoid glycosides from Ajuga remota aerial parts. J Asian Nat Prod Res. 2007:9(7):617-29.

9. Manguro LOA, Lemmen P, Hao P. Iridoid glycosides from underground parts of Ajuga remota. Rec Nat Prod. 2011;5(3):147-57.

10. Israili ZH, Lyoussi B. Ethnopharmacology of the plants of genus Ajuga. Pak J Pharm Sci. 2009;22(4):425-62.

11. Hailu W, Engidawork E. Evaluation of the diuretic activity of the aqueous and $80 \%$ methanol extracts of Ajuga remota Benth (Lamiaceae) leaves in mice. BMC Complement Altern Med. 2014;14(135):1-8.

12. Pascaline J, Charles M, Lukhoba C, George O. Phytochemical constituents of some medicinal plants used by the Nandis of South Nandi District, Kenya. J Animal Plant Sci. 2011;9(3):1201-10.
13. Makonnen E, Debella A, Abebe D, Teka F. Analgesic properties of some Ethiopian medicinal plants in different models of nociception in mice. Phytother Res. 2003;17:1108-12.

14. Asres K, Bucar F, Kartnig T, Witvrouw M, Pannecouque C, De Clercq E. Antiviral activity against human immunodeficiency virus type 1 (HIV-1) and type 2 (HIV-2) of Ethnobotanically selected Ethiopian medicinal plants. Phytother Res. 2001;15:62-9.

15. Nasser I, Getachew M, Tesfaye B, Mudiey K, Teka F. Anti-oxidant activity of 80\% methanol extracts from Clerodendron myricoides, Satureja punctata, Urtica dioica, Ajuga remota and Gnidia stenophylla. Revista CENIC. Ciencias Biológicas. 2010:41:17.

16. Wagate CG, Mbaria JM, Gakuya DW, Nanyingi MO, Kareru PG, Njuguna A, et al. Screening of some Kenyan medicinal plants for antibacterial activity. Phytother Res. 2010;24:150-3.

17. Vogel HG, Vogel WH, Scholkens BA, Sandow J, Muller G, Vogel WF. Drug discovery and evaluation: pharmacological assays. 2nd ed. Berlin: Springer-Verlag Heidelberg; 2002

18. Yadav AK, Tangpu V. Antidiarrheal activity of Lithocarpus dealbata and Urena lobata extracts:therapeutic implications. Pharm Biol. 2007;45(3):223-9.

19. Maxwell El, thechiluru El, Kelechi MG, Nkiru UE, Iheanacho UA, Stella AC, et al. Antidiarrheal activity of Pterocarpus erinaceus methanol leaf extract in experimentally-induced diarrhea. Asian Pac J Trop Med. 2012;20:147-50.

20. Bakare Rl, Magbagbeola OA, Akinwande Al, Okunowo OW, Green M. Antidiarrhoeal activity of aqueous leaf extract of Momordica charantia in rats. J Pharmacogn Phytother. 2011;3(1):1-7.

21. Shakuntala, Bharti P, Sachan N, Chandra P, Gahlot K. Evaluation of antidiarrhoeal activity of extract from roots of Rumex hastatus (family: Polygonaceae) on experimental animals. J Appl Pharm Sci. 2011;1(6):182-5.

22. Al-Taher AY. Possible antidiarrhoeal effect of the date palm (Phoenix Dactylifera L) spathe aqueous extract in rats. Sci J King Faisal University (Basic and Applied Sciences). 2008;9(1):131-8.

23. Hussain Z, Amresh G, Singh S, Rao CV. Antidiarrheal and antiulcer activity of Amaranthus spinosus in experimental animals. Pharm Biol. 2009:47(10):932-9.

24. Iqbal PJ. Phytochemical screening of certain plant species of Agra city. Drug Deliv Ther. 2012;2(4):135-8.

25. Trease GE, Evans WC. A textbook of pharmacognosy. 14th ed. London: Bailliere Tindall Ltd; 1996

26. Meite S, N'guessan JD, Bahi C, Yapi HF, Djaman AJ, Guede Guina F. Antidiarrheal activity of the ethyl acetate extract of Morinda morindoides in rats. Trop J Pharm Res. 2009;8(3):201-7.

27. Islam AMT, Uddin ME, Chowdhury MAU, Rahman MM, Habib MR, Rahman MA. In vivo Antidiarrheal and cytotoxic potential of different fractions of Pandanus Foetidus leaves. Am J Biomed Sci. 2013;5(3):208-16.

28. Karimulla S, Kumar BP. Pharmacological studies on anti-diarrhoeal activity of Morinda citrifolia (L.) in experimental animals. Int J Exp Pharmacol. 2011;1(1):12-6.

29. Mein EA, Richards DG, McMillin DL, Nelson CD. Transdermal absorption of castor oil. Evidence Based Integrative Med. 2005;2(4):239-44.

30. Rode MS, Kalaskar MG, Gond NY, Surana SJ. Evaluation of Antidiarrheal activity of diospyros malabarica bark extract. Bangladesh J Pharmaco. 2013;8:49-53.

31. Sarin RV, Bafna PA. Herbal antidiarrhoeals: a review. Int J Res Pharmaceut Biomed Sci. 2012;3:637-49. ISSN: 2229-3701.

32. Bhyrapur Mathad VS, Chandanam S, Thirumala Setty SR, Ramaiyan D, Veeranna B, Lakshminarayanasettry ABV. Antidiarrheal evaluation of Benincasa hispida (thunb.) cogn. Fruit extracts. IJPT. 2005;4:24-7.

33. Awouters F, Niemegeers CJE, Lenaerts FN, Janscen PA. Delay of castor Oil diarrhea in rats: a New Way to evaluate inhibitors of prostaglandin biosynthesis. J Pharm Pharmacol. 1978:30:41-5.

34. Brun IY, Wang XP, Willemot J, Sevenet T, Demenge P. Experimental study of Antidiarrheal activity of Salicairine. Fundam Clin Pharmacol. 1998:12:30-60.

35. Ezenwali MO, Njoku OU, Okoli CO. Studies on the Antidiarrheal properties of seed extract of Monodora tenuifolia. Int J Appl Res Nat Products. 2010;2:20-6.

36. Pandey P, Mehta A, Hajra S. Antidiarrhoeal activity of ethanolic extracts of Ruta graveolens leaves and stem. Asian J Pharm Clin Res. 2012;5(4):65-8.

37. Agbon AN, Kwaneshie HO, Hamman WO. Antidiarrheal activity of aqueous fruit extract of Phoenix dactylifera (DATE PALM) in Wistar rats. Br J Pharmacol Toxicol. 2013:4(3):121-7.

38. Gilani AH, Rehman N, Malik, Mehmood MH, Alkharfy KM. Species differences in the Antidiarrheal and antispasmodic activities of Lepidium sativum and insight into underlying mechanisms. Phytother Res. 2013;27:1086-94.

39. Pramod PS, Vishnu AN. Evaluation of anti-diarrheal activity of Ficus Glomerata in castor Oil induced diarrhoea in rats. J Mar Sci. 2011;1(1):26-30. 